\title{
GENERATION OF BUBBLES IN GLASS INSULATION LAYERS OF THE MC2730 RADIOISOTOPIC THERMO- ELECTRIC GENERATOR
}

R. J. Eagan and G. J. Jones

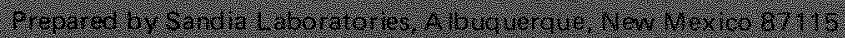




\section{DISCLAIMER}

This report was prepared as an account of work sponsored by an agency of the United States Government. Neither the United States Government nor any agency Thereof, nor any of their employees, makes any warranty, express or implied, or assumes any legal liability or responsibility for the accuracy, completeness, or usefulness of any information, apparatus, product, or process disclosed, or represents that its use would not infringe privately owned rights. Reference herein to any specific commercial product, process, or service by trade name, trademark, manufacturer, or otherwise does not necessarily constitute or imply its endorsement, recommendation, or favoring by the United States Government or any agency thereof. The views and opinions of authors expressed herein do not necessarily state or reflect those of the United States Government or any agency thereof. 


\section{DISCLAIMER}

Portions of this document may be illegible in electronic image products. Images are produced from the best available original document. 
Issued by Sandia Laboratories, operated for the United States Energy Research and Development Administration by Sandia Corporation.

\section{NOTICE}

This report was prepared as an account of work sponsored by the United States Government. Neither the United States nor the United States Energy Research and Development Administration, nor any of their employees, nor any of their contractors, subcontractors, or their employees, makes any warranty, express or implied, or assumes any legal liability or responsibility for the accuracy, completeness or usefulness of any information. apparatus, product or process disclosed, or represents that its use would not infringe privately owned rights. 
SIA $-74-0086$

GENERATION OF BUBBLES IN GIASS INSULATION LAYERS

OF THE MC2730 RADIOISOTOFIC THERMOELECTRIC GENERATOR

R. J. Eagan

Ceramics Development Division-5846

G. J. Jones

Radioisotope Power Sources Division-2334

Sandia Laboratories, Albuquerque, New Mexico 87115

March 1975

Hot-stage microscopy, residual gas analysis, and infrared transmission techniques were used to study the origin of bubbles or voids in the glass insulating layers of the MC2730 Radioisotopic Thermoelectric Generator (RTG). It was found that at temperatures above $1140 \mathrm{~K}, \mathrm{H}_{2}$ gas was generated through the reduction of water in the glass by the siGe alloy. It is suggested that voids were formed in those glasses which have low gas permeabilities because $\mathrm{H}_{2}$ was trapped at the interface. The formation of these voids was eliminated by restricting the fabrication temperatures to below $1140 \mathrm{~K}$.

This report was prepared as an account of work
sponsored by the United States Government. Neither
the United States nor the United States Energy
Research and Development Administration, nor any of
their employees, nor any of their contractors,
subcontractors, or their employees, makes any
warranty, express or implied, or assumes any legal
liability or responsibility for the accuracy, completeness
or usefulness of any information, apparatus, product or
process disclosed, or represents that its use would not
infringe privately owned rights.


BLANK 
TABIE OF CONTENTS

IIST OF FIGURES

INTRODUCTION

$\begin{array}{ll}\text { EXPERIMENT AND RESUITS } & 7\end{array}$

Observation of SiGe-Glass Reactions 7

Identification of Evolved Gases 8

Infrared Measurement of Water in Glass 9

The Role of Gas Permeability of the Glass 14

in Bubble Formation

$\begin{array}{ll}\text { DISCUSSION } & 16\end{array}$

$\begin{array}{ll}\text { CONCLUSIONS } & 17\end{array}$

$\begin{array}{ll}\text { REFERENCES } & 18\end{array}$ 
3 (a), (b) RGA spectra of melting glass showing (a) a bubble burst consisting mostly of $\mathrm{CO}$ and $\mathrm{CO}_{2}$ and (b) burst consisting mostly of $\mathrm{H}_{2} \mathrm{O}$.

4 (a), (b) RGA spectra showing large increase in hydrogen peaks associated with crushing bubbles in glass. (a) before, (b) immediately after crushing. glasses showing absorption peaks at 2.8 and $3.6 \mu \mathrm{m}$. concentration of glass former. Note: Permeabilities for 7059 and SIS glasses were estimated from their compositions. The permeabilities of the other glasses were measured by Altemose. 5 


\section{INTRODUCTION}

To form the thermopile used in the MC2730 radioisotopic thermoelectric generator (RTG), ${ }^{I}$ alternate layers of $\mathrm{p}$ - and $\mathrm{n}$-doped silicon germanium alloy (80 at\% Si) are bonded together by a glass insulating layer approximately $0.025 \mathrm{~mm}$ thick (Figure 1). The thermal expansion of the glass should approximately match that of the SiGe alloy and the glass must flow at a temperature below which the SiGe alloy would be degraded (1523 K); however, it must be sufficiently viscous at the operating temperature of the RTG $(\approx 693 \mathrm{~K})$ to ensure that significant deformation of the thermopile will not occur during the life of the generator. These requirements ultimately led to three candidate glasses: Corning Glass Works Code 1720, 7059, and 7052. Their compositions and properties are summarized in Tables I and II.

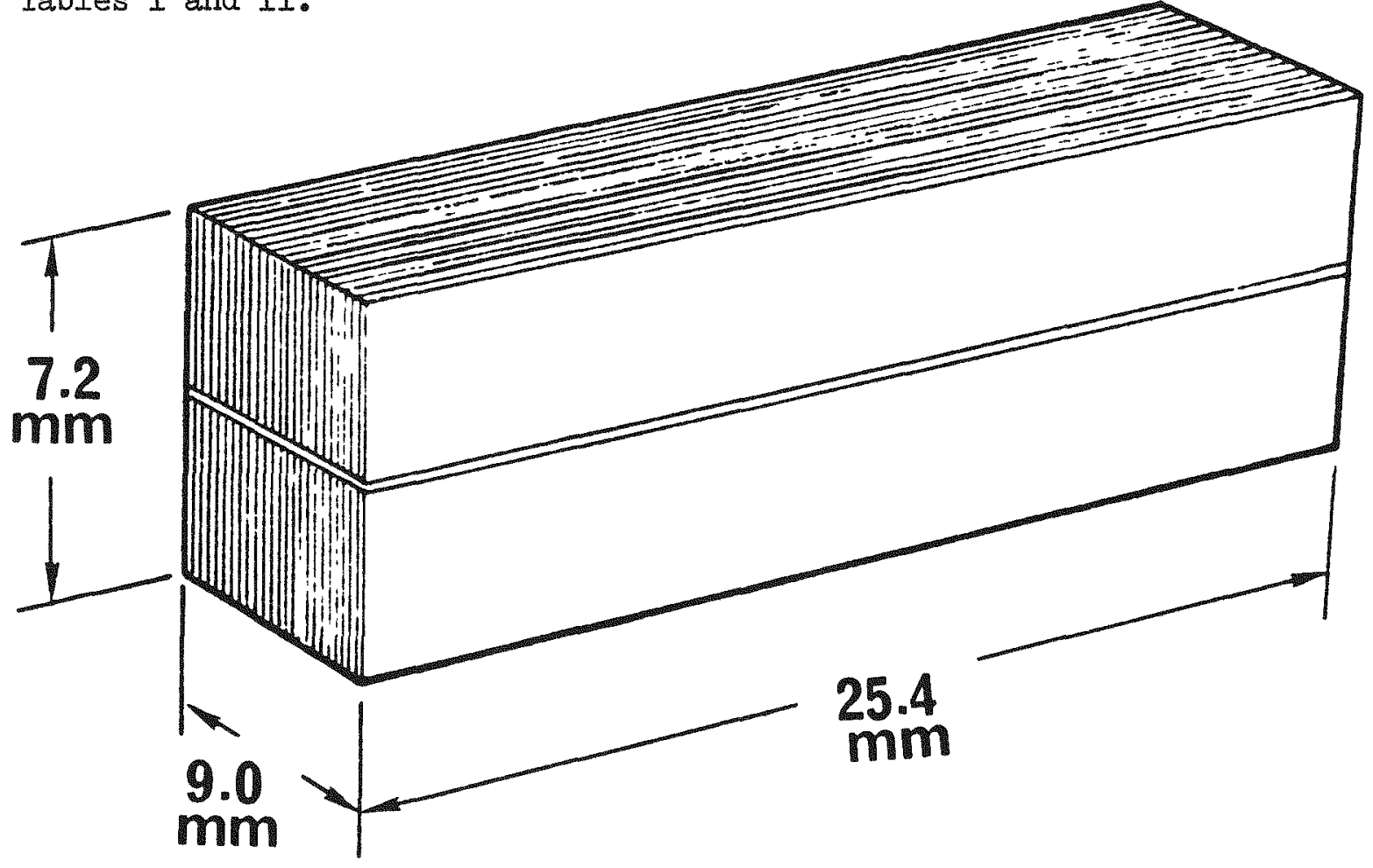

Figure I. Schematic of RTG thermopile. 
Table I. Composition of Corning Glasses

\begin{tabular}{|ccccccc|}
\hline & \multicolumn{2}{c}{ CODE 1720} & \multicolumn{2}{c}{ CODE } & CO52 & \multicolumn{2}{c|}{ CODE 7059} \\
& wt\% & mole\% & wt\% & mole\% & wt\% & mole\% \\
\hline $\mathrm{SiO}_{2}$ & 57 & 59 & 66 & 71 & 49 & 62 \\
$\mathrm{~B}_{2} \mathrm{O}_{3}$ & 4 & 4 & 18 & 17 & 13 & 14 \\
$\mathrm{AI}_{2} \mathrm{O}_{3}$ & 20.5 & 12.0 & 7.0 & 4.2 & 14 & 11 \\
$\mathrm{CaO}$ & 5.5 & 6.0 & -- & -- & -- & -- \\
$\mathrm{MgO}$ & 12 & 18 & -- & -- & 0.8 & 1.5 \\
$\mathrm{BaO}$ & -- & -- & 3.0 & 1.3 & 23.0 & 11.4 \\
$\mathrm{Na}_{2} \mathrm{O}$ & 1 & 1 & 2.0 & 2.1 & -- & -- \\
$\mathrm{K}_{2} \mathrm{O}$ & -- & -- & 3.0 & 2.1 & -- & -- \\
$\mathrm{Li}_{2} \mathrm{O}$ & -- & -- & 1.0 & 2.2 & -- & -- \\
$\mathrm{As}_{2} \mathrm{O}_{3}$ & -- & -- & -- & -- & 0.2 & 0.1 \\
\hline
\end{tabular}

Table II. Properties of Corning Glasses CODE 1720

Expansion

Coefficient

$\times 10^{6}$

$\begin{array}{lclr}273-573 \mathrm{~K} & 4.2 & 4.6 & 4.67 \\ \text { Softening Point, K } & 1188 & 983 & 1115 \\ \text { Annealing Point, K } & 988 & 753 & 908 \\ \text { Strain Point, } \mathrm{K} & 943 & 708 & 860 \\ \text { Density }\left(\mathrm{g} / \mathrm{cm}^{3}\right) & 2.52 & 2.25 & 2.76\end{array}$


In the early stages of development of the thexmopile, elimination of voids in the glass insulating layer proved to be difficult. Modifications of the process, including the use of vacuum hot pressing, reduced the number of the pores; however, it was eventually concluded that some of the pores were produced by a high-temperature reaction between the glass and the SiGe (Figure 2).

The purposes of this study were to determine the origin of bubbles (voids) in the glass insulation layer and to suggest ways to reduce or eliminate the voids.

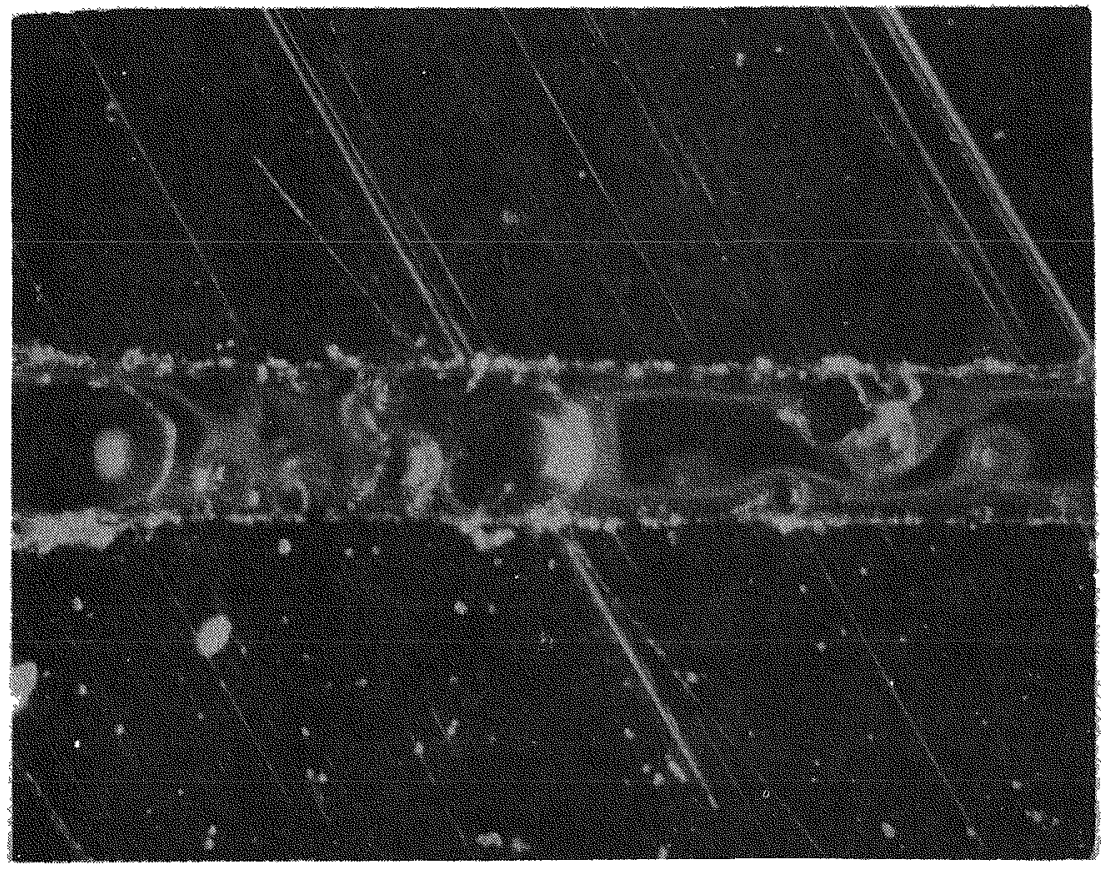

F'igure 2. RIG thermopile with voids in glass insulation.

EXXPERTMENT AND RESULTS

\section{Observation of SiGe-Glass Reactions}

The initial experiments were directed toward establishing the conditions that were required for the formation of bubbles and determining 
which gases formed them. To ascertain the temperature at which reaction between the glass and SiGe alloy occurred, a chip of each of the three candidate glasses was placed on a SiGe plate and heated in a hot-stage micros cope. ${ }^{\dagger}$

When a temperature of $1200 \mathrm{~K}$ was attained, bubbles formed in two of the glasses, Code 1720 and Code 7059. No bubbles were formed in Code 7052 glass at temperatures up to $1473 \mathrm{~K}$, the operating limit of the hot stage. To determine if the Ge from the SiGe played a vital part in generating bubbles, a comparison was made between melting on SiGe and on pure Si. Because there was no detectable difference, Si was used for most of the experiments in this study. Observation of the glass melting on substrates of Pt and $\mathrm{Al}_{2} \mathrm{O}_{3}$ substantiated that, for melting under atmospheric pressure, bubbles appeared only when $\mathrm{Si}$ or silicon alloys were the substrates. This experiment confirmed the proposal that some type of reaction was occurring, rather than simply the desorption of adsorbed gases.

\section{Identification of Evolved Gases}

To determine what gases were being evolved during firing, the glasses were heated on $\mathrm{Si}$, Pt, and $\mathrm{Al}_{2} \mathrm{O}_{3}$ substrates in a vacuum system with a residual gas analyzer attached. The bursting of a bubble in the glass, observed through the quartz furnace tube, was correlated with the appearance of peaks on the RGA. Because the glasses were melted in a vacuum, bubbles were formed when the glasses were melted on $\mathrm{Pt}, \mathrm{Al}_{2} \mathrm{O}_{3}$, and Si substrates.

\footnotetext{
†Litz 1350 Heating Stage, $\mathrm{E}$. Leitz, Inc., Rockleigh, NJ

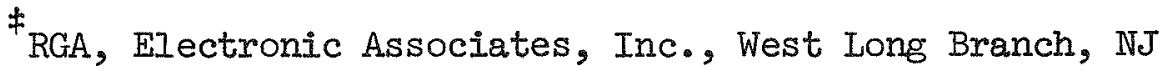


A typical RGA spectrum which resulted from detection of the gases evolved during melting in a vacuum is shown in Figure 3. The RGA spectra from glasses heated on Si, Pt, and $\mathrm{Al}_{2} \mathrm{O}_{3}$ were identical except for the occasional presence of an $\mathrm{H}_{2}$ peak from the glasses melted on Si. Bubble formation typically started at approximately $1150 \mathrm{~K}$. The gases were principally $\mathrm{H}_{2} \mathrm{O}, \mathrm{CO}_{2}$, and $\mathrm{CO}$.

Because it was not clear from these measurements which gas was forming the bubbles, glass which contained bubbles formed by melting the glass on Si, in air, was crushed in the RGA vacuum system. The gas contained in the bubbles was almost entirely hydrogen. A slight increase in the water peak (Figure 4) was also detected. $\mathrm{CO}_{2}$ and $\mathrm{CO}$, the other dissolved gases, were not observed in the bubbles.

It is not surprising that $\mathrm{H}_{2} \mathrm{O}$ and $\mathrm{CO}_{2}$ appeared in the $\mathrm{RGA}$ spectrum during melting of the glass in a vacuum. Generally, $\mathrm{H}_{2} \mathrm{O}, \mathrm{CO}_{2}, \mathrm{CO}$, and sometimes $\mathrm{SO}_{2}$ are present in production tanks and they are often dissolved in glasses during melting. They usually have little effect on optical and mechanical properties of the glass and their presence is often ignored. However, the preceding experiments showed that dissolved water causes the generation of bubbles in the glass when the glass is melted on Si. Infrared Measurement of Water in Glass

There are at least two explanations for the difference in bubble formation for the different glasses examined. One is that water was bonded in 1720 and 7059 in a way which prevented the reduction reaction from occurring, whereas in 7052 it was not. The other possibility is that gas is generated in every case where there is water initially dissolved in the glass, but that in 7052 the gas does not coalesce into bubbles. 


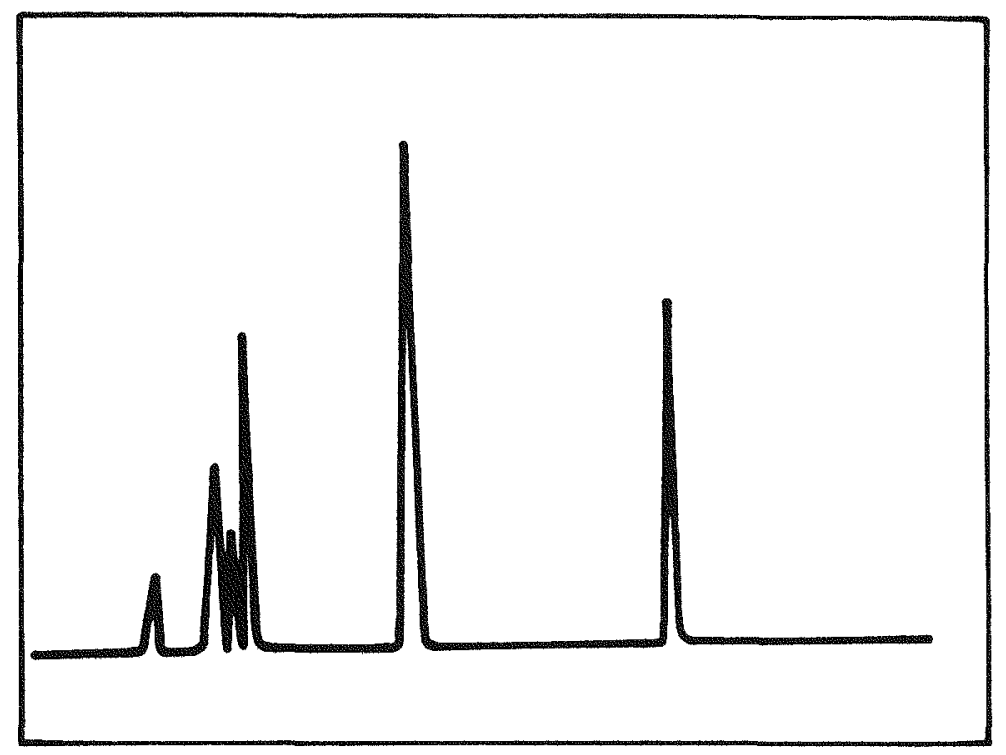

(a)
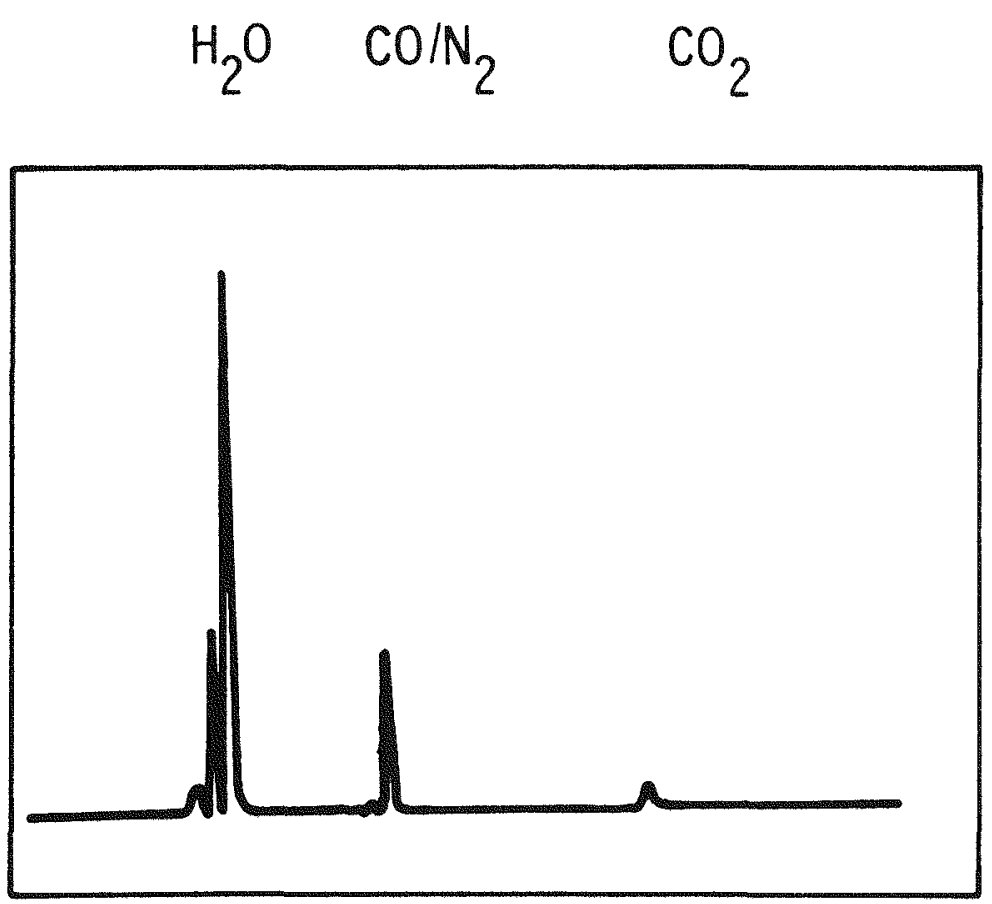

(b)

Figure 3 (a), (b). RGA spectra of melting glass showing (a) a bubble burst consisting mostly of $\mathrm{CO}$ and $\mathrm{CO}_{2}$ and (b) burst consisting mostly of $\mathrm{H}_{2} \mathrm{O}$. 


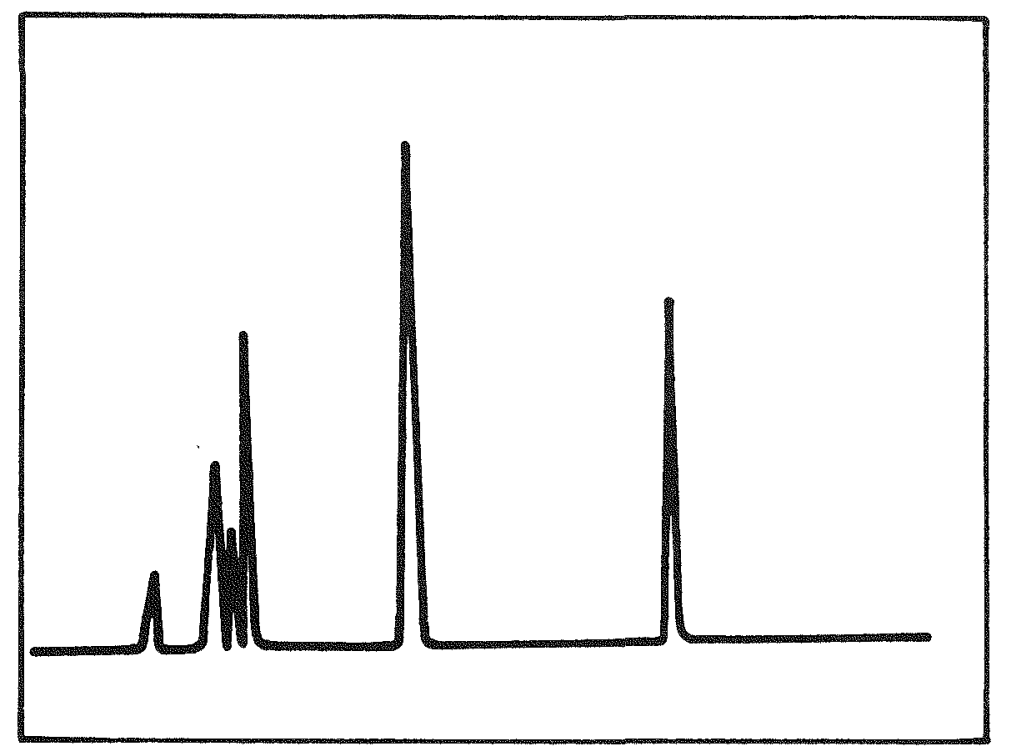

(a)

$\mathrm{H}_{2} \mathrm{O} \quad \mathrm{CO} / \mathrm{N}_{2} \quad \mathrm{CO}_{2}$

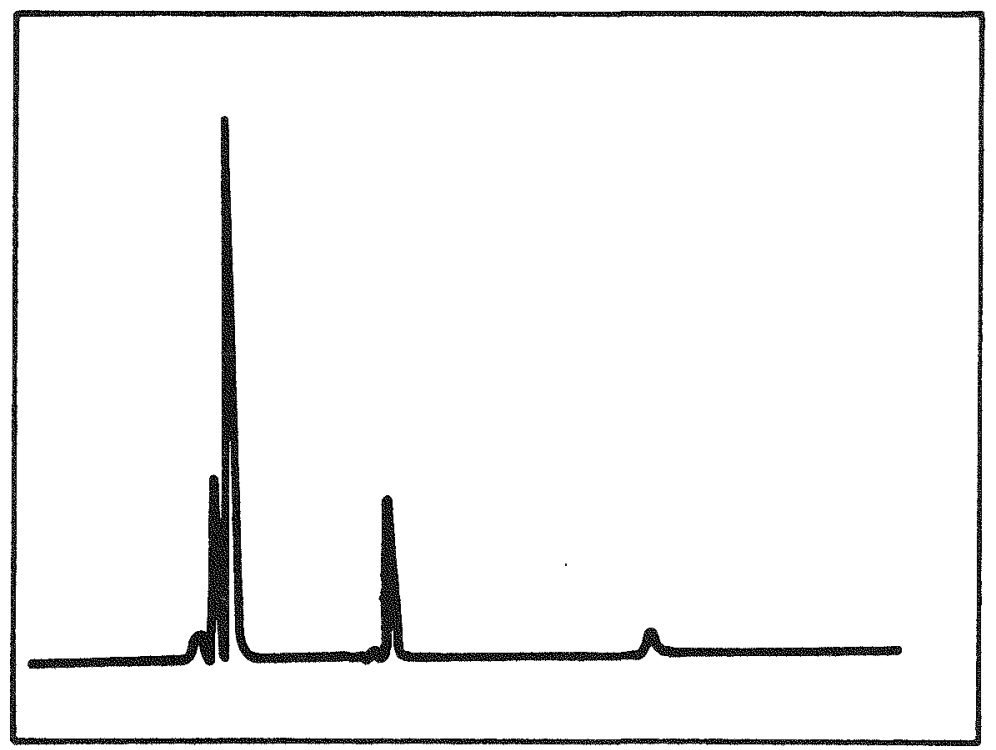

(b)

Figure 4 (a), (b). RGA spectra showing large increase in hydrogen peaks associated with crushing bubbles in glass。 (a) before, (b) immediately after crushing. 
One method for determining the strength of the $\mathrm{OH}$ bonds and the position of the water in the glass network is to examine the infrared transmission spectrum in the range $2.7 \mu \mathrm{m}$ to $5 \mu \mathrm{m}^{2}$ Figure 5 shows the absorption spectrum for the glasses of interest as well as for a relatively water-free silica glass. The positions of the peaks indicate the types of bonds the water forms with the glass network; i.e., $2.84 \mathrm{~mm}$ (SiOH), 3.6 and $4.25 \mu \mathrm{m}(\mathrm{SiO}-\mathrm{H}-\mathrm{OSi})$. Generally the $4.25 \mu$ peak is small and is obscured by the Si-O absorption. The magnitudes of the absorptions can be used to calculate the concentration of water in the glass. ${ }^{3}$

From the fact that the SiOH peak occurred at the same wavelength $(2.85 \mathrm{\mu m})$ for each glass, it can be concluded that there was no significant difference in the strength of the SiOH bond. The hydrogenbonded water peak at $3.6 \mu \mathrm{m}$ was obscured in each glass because of the boron-oxygen-boron absorption in the same region of the spectrum. However, it can be argued that in these glasses no hydrogen-bonded water exists. Sholze ${ }^{3}$ has shown that when the $\mathrm{Al}_{2} \mathrm{O}_{3}: \mathrm{M}_{2} \mathrm{O}$ ratio is $I$ in silicate glass, nonbridging oxygen ions are eliminated; therefore, the water in a glass is not hydrogen bonded, i.e., the $3.6 \mu \mathrm{m}$ peak is not observed. Weyl ${ }^{4}$ has proposed that the coordination of boron in a glass is similar to that of $\mathrm{Al}$; therefore, a $\mathrm{B}_{2} \mathrm{O}_{3}: \mathrm{M}_{2} \mathrm{O}$ ratio of I should eliminate the hydrogen-bonded water. Because the ratio of $\mathrm{B}_{2} \mathrm{O}_{3}+\mathrm{Al}_{2} \mathrm{O}_{3}: \mathrm{M}_{2} \mathrm{O}$ is $\geq 1$ for 7052 and 7059 and nearly $I$ for 1720 , it may be concluded that all of the water is bonded as SiOH groups in each glass. 


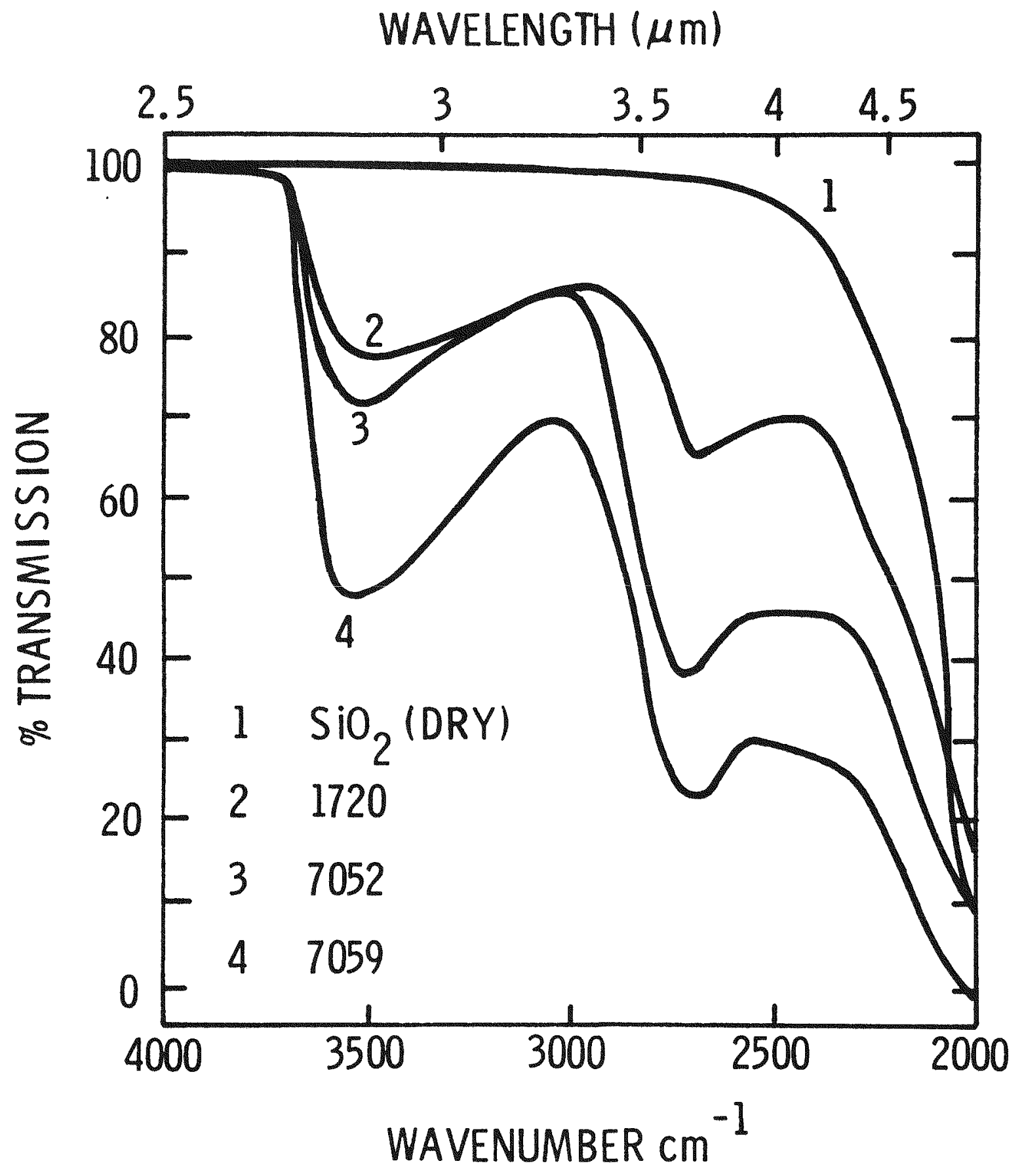

Figure 5. Infrared transmission spectra of several glasses showing absorption peaks at 2.8 and $3.6 \mu \mathrm{m}$. 
The concentration of water in each glass was calculated from the Beer-Lambert equation:

$$
C=\frac{I}{d \varepsilon} \log \frac{1}{T}
$$

where:

$$
\begin{aligned}
& \mathrm{C}=\text { concentration in moles/liter } \\
& \mathrm{d}=\text { thickness of specimen }(\mathrm{cm}) \\
& \epsilon=\text { molar extinction coefficient } \\
& \mathrm{T}=\text { percent transmission. }
\end{aligned}
$$

Scholze's $\mathrm{s}^{3}$ value of $70 \mathrm{\ell}$ mole $\mathrm{cm}^{-1}$ was used for the molar extinction coefficient for the Si-OH absorption. The amount of water in Code 7052 and Code 7059 was calculated to be $0.05 \mathrm{wt} \%$ and $0.03 \mathrm{wt} \%$ was calculated to be present in Code 1720.

\section{The Role of Gas Permeability of the Glass in Bubble Formation}

Because each glass contained approximately the same concentration of water and no detectable difference in the bonding of water into the glass network was found, it was concluded that $\mathrm{H}_{2}$ should have been generated when each glass was melted on Si. It was proposed, therefore, that the formation of bubbles may be related to the difference in the capacity of each glass to take $\mathrm{H}_{2}$ into solution and allow it to diffuse away from the interface. The permeability, i.e., the product of the diffusivity and solubility, of glasses to gases changes approximately four orders of magnitude over the composition range typically found in commercial glasses. Altemose 5 has shown that the $\log$ permeability of He changes linearly with the mole $\%$ glass former in this composition range (Figure 6)。 For the few glasses 


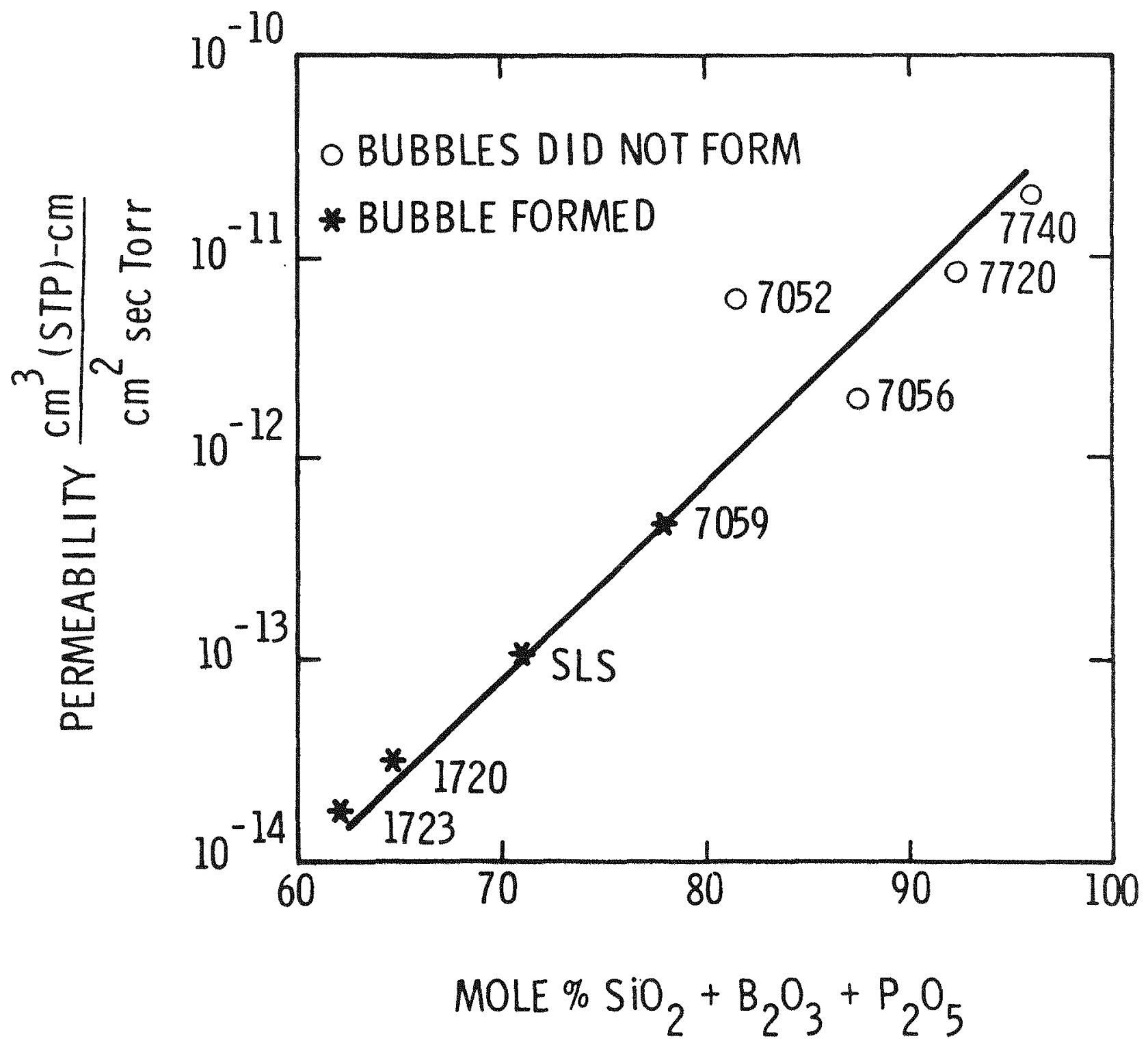

Figure 6. Permeability of glasses to He related to concentration of glass former. Note: Permeabilities for 7059 and SLS glasses were estimated from their compositions. The permeabilities of the other glasses were measured by Altemose. 5 
which have been measured, the permeability of glasses to $\mathrm{H}_{2}$ shows a similar behavior but is several orders of magnitude lower. Glasses with high permeability might be expected to release the hydrogen so that bubbles would not form.

To further test the proposal that permeability affects bubble formation, several additional glasses were melted on $\mathrm{Si}$ to determine which ones would form bubbles. The compositions of the glasses ranged from 63 mole \% glass former (Code 1723) to 95\% glass former (Code 7740). The results are indicated in Figure 6. Although, as shown by IR analysis, all of the glasses contained $\mathrm{H}_{2} \mathrm{O}$, only those with lower permeability, i。e., Code I720, 1723, 7059, and SLS (soda-Iime-silica), produced bubbles。 The glasses with greater gas permeability did not produce bubbles, i.e., 7052, 7720, 7740 , and 7056.

\section{DISCUSSION}

This study has shown that water, chemically bonded in glass as $\mathrm{OH}$ groups, can be reduced by $\mathrm{Si}$ to form $\mathrm{H}_{2}$ at temperatures above $1140 \mathrm{~K}$. It is suggested that the $\mathrm{H}_{2}$ generated by this reaction can dissolve and diffuse away from the glass-Si interface in glasses which have relatively high permeabilities to gases. The gas is trapped at the interface and forms bubbles in glasses with low gas permeabilities.

The limitation imposed by the design of the RTG dictated the use of Code 7059 glass to obtain sufficient mechanical strength at operating temperatures. Attempts made to remove water from the glass by vacuum melting the glass were successful; however, when the vacuum-melted glass was ground to make a powder for coating the SiGe plates, sufficient water 
reacted with the glass to cause the formation of bubbles during subsequent processing.

One potential solution to this problem would have been to design a refractory glass with the correct thermal expansion and a higher gas permeability. However, the time involved in development of the new glass and the difficulty of supplying the special glass for production of the thermopiles argued against this course of action.

The more immediate and practical solution was to adjust the thermopile fabrication process to keep the processing temperatures below the temperature at which the reaction starts (1140 K). This specification has been incorporated into the thermopile processing, along with a vacuum bakeout to remove adsorbed gases. The glass insulation layers are generally free of voids when thermopiles are processed in this way.

\section{CONCLUSIONS}

It has been shown that the formation of voids in the glass insulating layers of the MC2730 RTG can result from the reduction of water in the glass to form $\mathrm{H}_{2}$. To avoid this reaction a temperature limit of $1140 \mathrm{~K}$ was imposed on thermopile fabrication. 


\section{REFERENCES}

1. E. K. Beauchamp and J. Matsko, "Development of the Glass Bonding Process for the MC2730 Thermopile," SIA-73-0912 (September 1974).

2. H. Scholze, "The Incorporation of Water in Glasses," Glastech. Ber. 32 (3), 81 (1959)。

3. H. Scholze, "Gases and Water in Glass, Part II," The Glass Industry 47 (11), 662 (1966).

4. W. A. Weyl and E. C. Marboe, The Constitution of Glasses: A Dynamic Interpretation (Interscience Publishers, New York, 1964), Part I, Vol. II, pp。 554-566.

5. V. O. Altemose, "Helium Diffusion Through Glass," J.Appl. Phys. $32(7), 1309$ (196I).

6. J. E. Shelby, "A Comprehensive Review of Gas Permeation, Diffusion, and Solubility in Inorganic Glasses," SLI-73-0259 (August 1973)。 
Distribution:

Art Kuntz

General Electric Company

Neutron Devices Department

P.O. Box 11508

St. Petersburg, FL 33733

2300 I. D. Smith

2310 C.B. McCampbe11

2320 Ko Gillespie

2330 J. P. Shoup

2331 A. I. Thornton

2334 M. K. Parsons

2334 G. J. Jones (10)

2336 J. P. Ford

2340 T. S. Church

5000 A. Narath

Attn: 5100 J. K. Galt

5200 E. H. Beckner

5600 A. Y. Pope

5700 J. H. Scott

5800 I. M. Berry

Attn: 5810 R. Go Kepler

5820 R. I. Schwoebel

5840 D. M. Schuster

5830 M. J. Davis

5842 R. C. Heckman

5844 F. P. Gerstle, Jr.

5846 E. K. Beauchamp

5846 R. J. Eagan (10)

5847 C. H. Karnes

8334 J. E. Shelby

3151 Technical Writing (3) for AEC/TIC

3141 Classification (5)

8266 Iibrary (2) 